\title{
AVALIAÇÃO DA INFLUÊNCIA DA ATMOSFERA DE SINTERIZAÇÃO DO COMPOSTO INTERMETÁLICO AI12Si*
}

Magnos Marinho da Silva ${ }^{1}$ Sandro Luís Arenhardt ${ }^{1}$ Guilherme Santos Garcia ${ }^{2}$ Vinícius Martins ${ }^{3}$

Marcus Aurélio dos Santos ${ }^{1}$ Alexandre da Silva Rocha ${ }^{4}$

\section{Resumo}

A Metalurgia do Pó é um processo de conformação mecânica com um grande crescimento de sua aplicação no cenário industrial brasileiro, por possuir um vasto campo de aplicação que inclui, por exemplo, a fabricação de componentes automotivos, eletrodomésticos, ferramentas de corte e ferramentas elétricas. A sinterização é a fase mais importante do processo, no qual o pó já compactado é submetido a uma temperatura abaixo do seu ponto de fusão, obtendo como resultado um material com excelente acabamento, precisão dimensional e propriedades mecânicas. O trabalho apresentado tem como objetivo avaliar o comportamento do composto intermetálico denominada de Al12Si com a composição de $12 \%$ de $\mathrm{Si}, 1,14 \%$ de $\mathrm{Ni} ; 1,08 \%$ de $\mathrm{Mg} ; 0,45 \% \mathrm{Fe} ; 1,08 \%$ de $\mathrm{Cu}$ e Al em balanceamento. Foi sinterizado com gás argônio para fazer um comparativo do mesmo material, porém utilizando uma atmosfera de nitrogênio. Tendo como objetivos específicos realizar levantamentos sobre a densidade, microdureza e metalografia apresentados em função das cargas aplicadas em cada uma das amostras. Comparar a influência do tratamento térmico T6 na dureza dos materiais em função da atmosfera de sinterização. A metalografia apresentou porosidade inerente ao processo, mas houve um acréscimo de microdureza entre as amostras produzidas em atmosfera com argônio e as produzidas com atmosfera com nitrogênio com uma variação de 59,51 HV-50g. para 72,30 HV-50g.

Palavras-chave: Metalurgia do pó; Composto alumínio; Microdureza; Densidade e metalografia.

\section{INFLUENCE EVALUATION OF SINTERING ATMOSPHERE OF INTERMETALLIC COMPOUND Al12Si}

\begin{abstract}
The Powder Metallurgy is a metal forming process with a large growth of its application in the Brazilian industrial scenario, as it has a vast scope that includes, for example, the manufacture of automotive components, home appliances, cutting tools and power tools. Sintering is the most important phase of the process, in which the already compacted powder is submitted to a temperature below its melting point, obtaining a material with excellent finish, dimensional accuracy and mechanical properties.

The work presented is to evaluate the intermetallic compound of the behavior called Al12Si with the composition of $12 \% \mathrm{Si}, 1.14 \% \mathrm{Ni} ; 1.08 \% \mathrm{Mg} ; 0.45 \% \mathrm{Fe} ; 1.08 \% \mathrm{Cu}$ and $\mathrm{Al}$ in balance. Argon gas was sintered to make a comparison of the same material but using a nitrogen atmosphere. Having specific objectives surveying on the density, hardness and metallography presented according to the loads applied on each sample. Compare the influence of the heat treatment T6 hardness of the material due to the sintering atmosphere. The metallography showed inherent porosity of the trial, but there was an increased microhardness of the samples produced in an atmosphere of argon and nitrogen atmosphere produced with a range of 59.51 to HV-50g. 72.30 to HV-50g.

Keywords: Powder metallurgy; Aluminum composition; Microhardness; Density and metallography.

1 Tecnologia em Fabricação Mecânica, Mestrando em Engenharia de Minas, Metalúrgica e Materiais, Universidade Federal do Rio Grande do Sul (UFRGS), Porto Alegre, RS, Brasil.

2 Eng. Mecânica, Mestrando em Eng. de Minas, Metalúrgica e Materiais, UFRGS, Porto Alegre, RS, Brasil.

3 Tecnologia em Fabricação Mecânica, professor do Instituto Federal Sul-rio-grandense, Doutor em Engenharia de Minas, Metalúrgica e Materiais, UFRGS, Porto Alegre, RS, Brasil.

4 Eng. Mecânica, Doutor Eng. de Minas, Metalúrgica e Materiais, professor, UFRGS, Porto Alegre, RS, Brasil.
\end{abstract}




\section{INTRODUÇÃO}

O desenvolvimento industrial da metalurgia do pó ocorreu no início deste século quando foi estudada a possibilidade de fabricação, por sinterização, de molibdênio e tungstênio, metais refratários. Sua obtenção por processos metalúrgicos convencionais era impossibilitada devido ao ponto de fusão apresentado, extremamente elevado. A produção de ligas duras sinterizadas a partir de carboneto de tungstênio aglomerados com metal do grupo do ferro e cobalto são utilizados na produção de misturas para materiais de contato elétrico e em diversas aplicações, pois praticamente todos os metais e ligas podem ser produzidos pela metalurgia do pó (CHIAVERINI, 2001).

A metalurgia do pó é potencialmente utilizada, ou uma alternativa muito atraente, na necessidade de produzir grandes lotes de peças, com complexidade de forma ou com material base de alto ponto de fusão. Este é um processo moderno, mas os avanços científicos e tecnológicos não param (GRUPO SETORIAL, 2009).

Alguns exemplos de produtos que são mais eficientes e economicamente fabricados pela metalurgia do pó são peças de grande precisão dimensional e de forma relativamente complexa, de ferro e aço, cobre e suas ligas, alumínio e suas ligas e outros metais e ligas. São muito utilizadas, em grande escala, nos mais variados setores de máquinas, veículos e equipamentos (CHIAVERINI, 2001).

Uma operação fundamental da técnica de metalurgia do pó é a sinterização, pois ela constitui a fase final do ciclo de consolidação dos pós-metálicos, ciclo esse iniciado com a compactação (Huo et al, 2011).

A metalurgia do pó tem a finalidade de transformar sem fusão efetiva, pós metálicos ou não metálicos usando pressão para compactação e calor, através de um tratamento térmico de sinterização, que se realiza a temperatura inferior ao ponto de fusão do material base do componente ou peça, permitindo obtê-los na sua forma final ou próximo dela ('near-net or net-shape') (SANDEROW, 1998).

A aplicação da metalurgia do pó oferece três vantagens básicas: A primeira é o custo de produção menor, que compensa o fato de o pó ter o preço superior ao das chapas e das barras metálicas. A segunda é a possibilidade de obter misturas que não se poderiam fazer por meio da fundição, como a composição de peças com ferro e alumínio. Além disso, o processo de produção é mais simples, o que permite a elaboração de componentes novos em menos tempo (SCHAFFER, 2010).

O processo de Metalurgia do Pó pode ser visto de maneira esquemática e simples através da Figura 1, demonstrada a seguir.

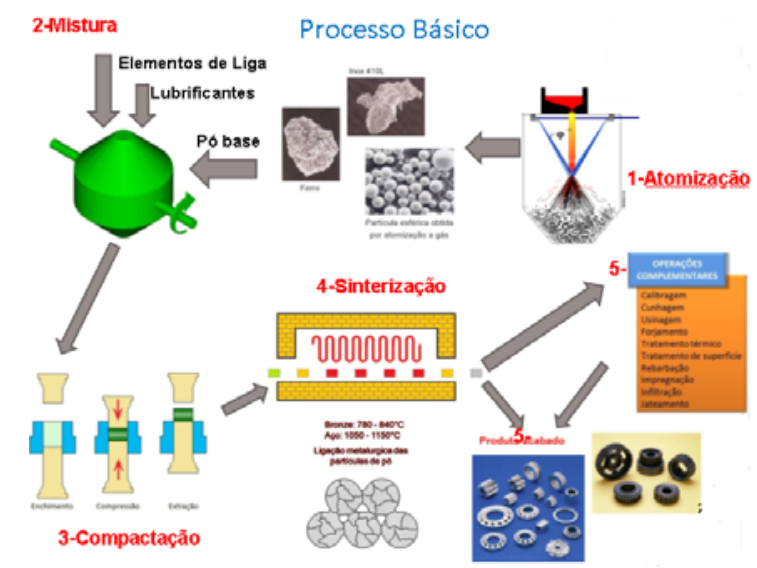

Figura 1: Processo Básico de metalurgia do pó http://slideplayer.com.br 
objetivo deste trabalho é avaliar comportamento do alumínio Al12Si sinterizado com gás argônio e fazer um comparativo do mesmo material porém submetido a sinterização por atmosfera de nitrogêneo. tendo como objetivos específicos realizar levantamentos sobre a densidade, microdureza e metalografia apresentados em função das cargas aplicadas em cada uma das amostras que foram compactadas com $600 \mathrm{MPa}$.

O tratamento térmico T6 é realizado o tratamento térmico de precipitação que compreende as seguintes etapas: solubilização, têmpera e envelhecimento artificial. (Menente e Tomelli, 2011). O endurecimento por precipitação é um tratamento térmico muito importante das ligas não-ferrosas, sendo utilizado tanto em ligas trabalhadas como em ligas fundidas, pois a escolha dos patamares de temperatura e tempo influenciaram diretamente as propriedades mecânicas. A condição necessária para que ocorra a precipitação é a existência de uma solução sólida supersaturada que é conseguida através da solubilização. Este tipo de tratamento térmico é comumente realizado em diversas ligas e compostos intermetálico de alumínio fundidos (Oliveira e Rocha, 2014).

\section{MATERIAIS E MÉTODOS}

Devido a não termos estudos suficientes em relação ao efeito do percentual de adição do cobre no alumínio, vislumbrou-se o estudo da caracterização deste composto a fim de obter dados concretos com a compactação e sinterização.

Para determinação do tamanho de partícula do aglomerado das amostras foram analisadas no microscópico eletrônico de varredura (MEV) do centro de microscopia da UFRGS, de marca JEOL modelo 5800 com EDS acoplado.

Os pós foram pesados a fim de obter os resultados de suas massas para os cálculos de percentual de cada elemento na mistura. Para a compactação das amostras foi utilizada uma matriz cilíndrica de aço temperado com diâmetro interno $(\varnothing)$ de $13 \mathrm{~mm}$ e $63 \mathrm{~mm}$ de altura $(\mathrm{h})$ da cavidade, com o punção superior de $15 \mathrm{~mm}$ de altura e o punção inferior de $65 \mathrm{~mm}$ de altura.

Com o objetivo de diminuir o atrito entre os componentes do ferramental de compactação, utilizou-se $1,5 \%$ de estereato de zinco da massa total da mistura em suas devidas porcentagens. Para realizar a prensagem do pó junto à matriz, foi utilizada uma prensa hidráulica da marca Bovenau, modelo P30st. As pressões de compactação utilizadas foram de 100Mpa até 1000MPa.

A fim de obter a resistência mecânica dos corpos de prova (peças verdes), as mesmas foram encaminhadas para o processo denominado sinterização. Durante esta fase do processo as amostras foram expostas a uma atmosfera controlada por meio de gás argônio. O aquecimento das amostras iniciou em temperatura ambiente $\left(18^{\circ} \mathrm{C}\right)$ e teve um aumentou gradativo com a taxa de $10^{\circ} \mathrm{C} / \mathrm{min}$ até alcançar o patamar térmico de sinterização com a temperatura de $500{ }^{\circ} \mathrm{C}$, onde permaneceu durante uma hora, realizando assim a sinterização completa e união das partículas metálicas.

Após uma hora de exposição das amostras à temperatura de $500{ }^{\circ} \mathrm{C}$, ainda mantendo as peças no interior do forno deu-se inicio o resfriamento destas amostras. O resfriamento atuou com uma taxa média decrescente de $9,53{ }^{\circ} \mathrm{C} / \mathrm{min}$ até atingir $200^{\circ} \mathrm{C}$, onde a temperatura passou a diminuir a uma taxa média de $5,83^{\circ} \mathrm{C} / \mathrm{min}$ até a temperatura ambiente, quando foram retiradas do forno.

Para a realização da micrografia através da microscopia óptica, as amostras foram submetidas ao procedimento de lixamento, realizado em uma politriz metalográfica 
onde foram utilizadas lixas de papel com abrasivo tipo $\mathrm{SiC}$ com granulometrias de número 120, 280, 320, 400, 600 e 1200, sempre trabalhando as amostras em $90^{\circ}$ de uma lixa para outra até desaparecerem os traços da lixa anterior. As amostras foram submetidas ao polimento com pano de feltro e com abrasivo de Óxido de Alumínio para deixar a superfície das amostras espelhadas. Na sequência, realizouse limpeza com água corrente e também com álcool.

Foi realizado o teste de Microdureza utilizando o microdurômetro ISH-TDV1000. Através da análise da Microdureza Vickers, com carga $50 \mathrm{~g}$, foi possível observar quais amostras apresentam as melhores condições mecânicas, levando em consideração a pressão utilizada durante o processo de compressibilidade. $O$ ensaio foi realizado utilizando cinco medições para aumentar a precisão dos resultados como está contida na Norma ASTM E 384.

Para a medição de densidade, as amostras foram medidas antes da sinterização a fim de se obter o volume e, com os valores de massa, calculadas as densidades. Após a sinterização, o volume das amostras foi medido através do Método de Arquimedes, o qual consiste em submergir a peça em um recipiente com água (este sobre uma balança de precisão) e, através deste método, é possível relacionar o volume de água deslocado com o volume total da peça. Por fim, a densidade dos sinterizados é calculada em função do volume obtido e a massa das peças. $O$ tratamento T6 foi aplicado em uma empresa fabricante de peças de alumínio em forno continuo. Os tratamentos térmicos de solubilização e envelhecimento artificial foram realizados à temperaturas de $540^{\circ} \mathrm{C}$ e $156^{\circ} \mathrm{C}$ com duração de cinco (5) horas e duas (2) horas, respectivamente. O tempo do tratamento de solubilização foi contado a partir do instante em que o forno alcançou a temperatura de $540{ }^{\circ} \mathrm{C}$. Depois analisou-se novamente as peças.

\section{RESULTADOS E DISCUSSÃO}

A Figura 2 apresenta a microscopia eletrônica de varredura do pó de alumínio com o formato tamanho e morfologia da partícula.

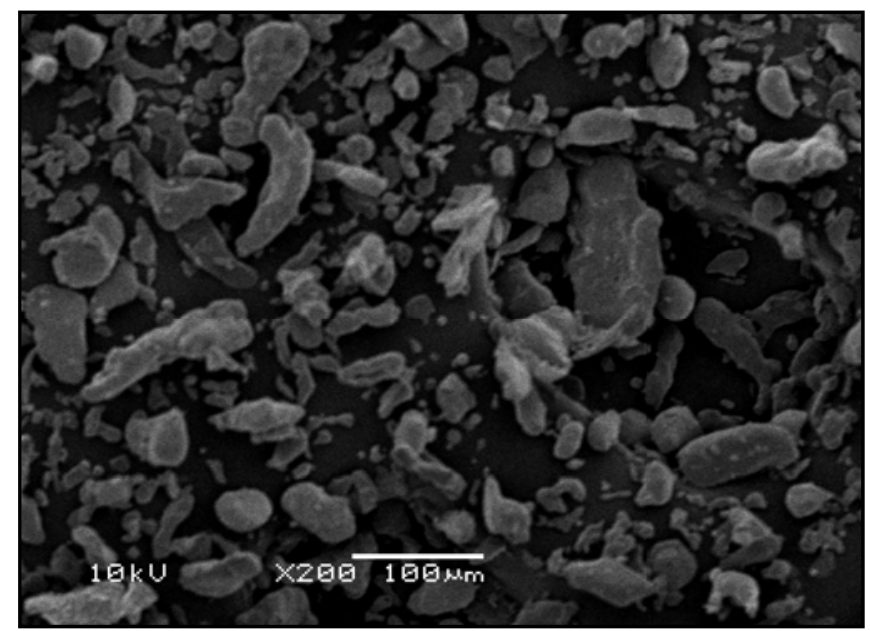

Figura 2: Micrografia do pó de alumínio da Alcoa

Observa que o pó de Aluminio apresenta diversos tamanhos, desde partícula com $10 \mu \mathrm{m}$ a menores que $100 \mu \mathrm{m}$ em diversos formatos, algumas partículas arredondadas, outras dendríticas. A Figura 3 apresenta a microscopia eletrônica de varredura do pó de cobre. 

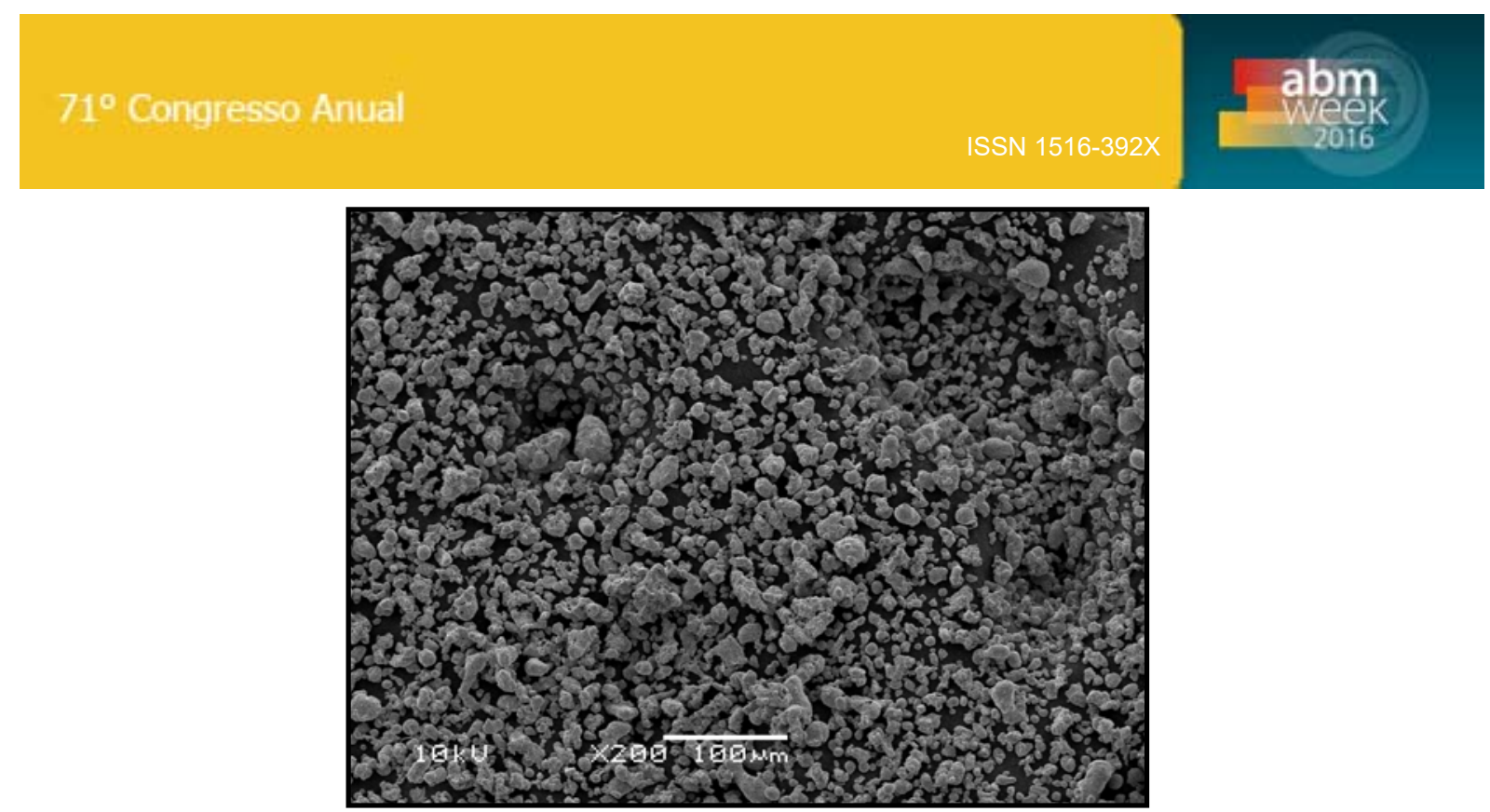

Figura 3: Micrografia do pó de Cobre

Notam-se partículas com tamanho próximas de $10 \mu \mathrm{m}$ até $20 \mu \mathrm{m}$ e formato arredondados. Na Figura 4 observa-se a curva de compressibilidade a verde do Al12\%Si versus a curva de de compressilbilidade do sinterizado.

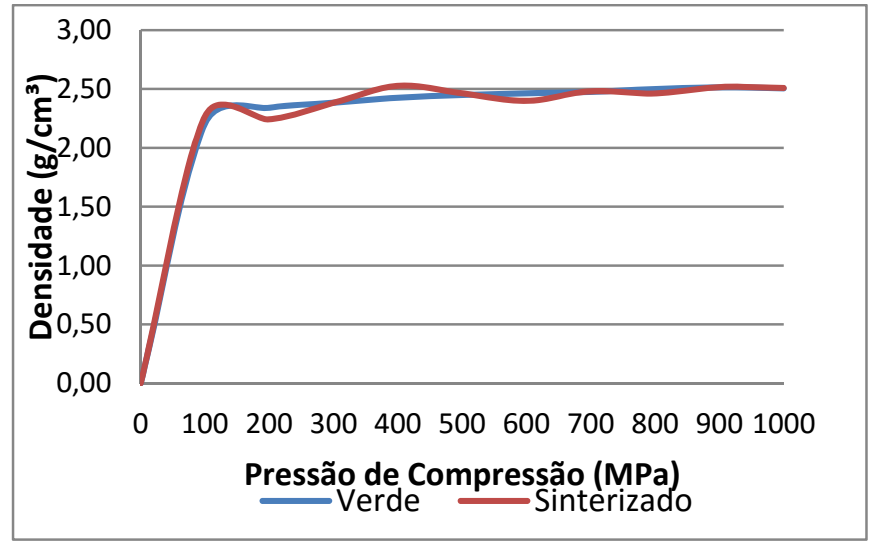

Figura 4: Curva de compressibilidade do Al12\%Si

Analisando a Figura 4 percebe-se que utilizando pressões de $400 \mathrm{MPa}$ tem-se a maior densificação do sinterizado em relação a peça verde. Nas pressões de compactação entre $500 \mathrm{MPa}$ e $600 \mathrm{MPa}$ a densidade das amostras começam a se estabilizar e pressões acima destes valores tornam-se desnecessários a compactação por não ter-se melhores resultados da densidade, ou seja, esforço dispensável o empregado no equipamento já que não há mudança significativa no resultado da compressibilidade. Também é observado que a adição de outros componentes no composto intermetálico, obteve-se a densidade calculada de 2,71 $\mathrm{g} / \mathrm{cm}^{3}$ similar ao do alumínio puro.

Observa-se na Figura 5 as amostras compactadas em diferentes pressões e sinterizadas com argônio, com patamar térmico de $600^{\circ} \mathrm{C}$. Nestas amostras foram realizadas o tratamento térmico $\mathrm{T} 6$ e posteriormente realizado o ensaio de microdureza. 


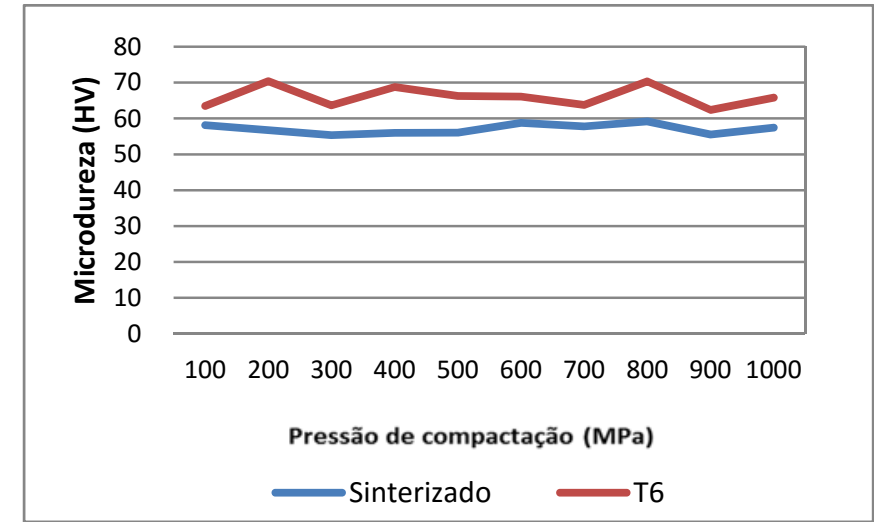

Figura 5: Comparação das microdurezas das amostras sinterizadas com argônio.

Analisando a Figura 5, verifica-se que os resultados dos sinterizados do composto Al12\%Si com atmosfera de argônio, após o tratamento térmico T6 foi obtida uma média de microdureza de $66,09 \mathrm{HV}-50 \mathrm{~g}$. O melhor resultado encontrado foi com a pressão de $800 \mathrm{MPa}$ e dureza de $70,35 \mathrm{HV} 50 \mathrm{~g}$, comparado-se com a microdureza encontrada no $\mathrm{Al} 12 \% \mathrm{Si}$ sem o tratamento térmico T6 observa-se que a média ficou com 54,89 HV-50g, obtendo assim um aumento de $19,5 \%$ na microdureza do composto $\mathrm{Al} 12 \% \mathrm{Si}$. Pode-se então concluir que após o tratamento térmico T6 as amostras tiveram um aumento de microdureza.

$\mathrm{Na}$ Figura 6, nota-se $\mathrm{o}$ as amostras compactadas em diferentes pressões e sinterizadas com nitrogênio, com patamar térmico de $600^{\circ} \mathrm{C}$. Nestas amostras foram realizadas o tratamento térmico T6 e posteriormente, o ensaio de microdureza, conforme pode ser observado.

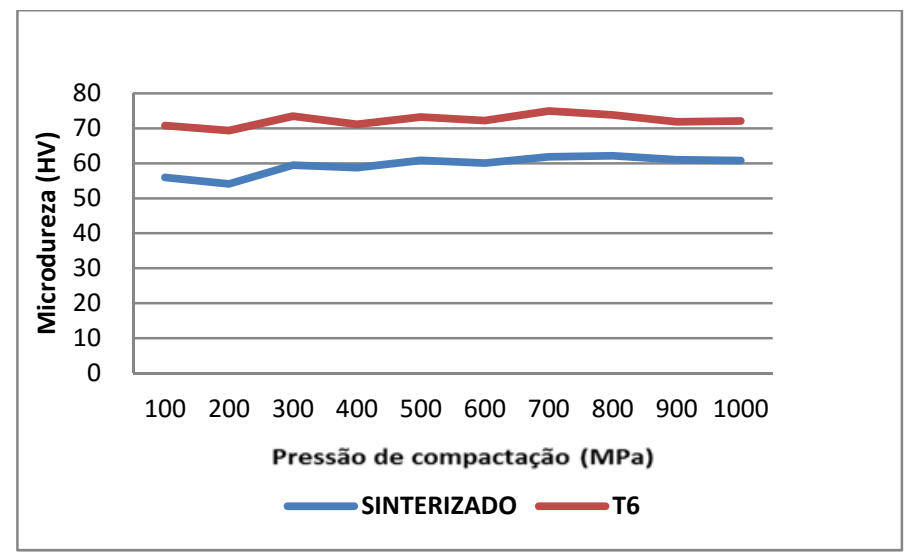

Figura 6: Comparação das microdurezas das amostras sinterizadas com nitrogênio

Analisando o gráfico, verifica-se que os resultados do sinterizado do composto de Al12\%Si com atmosfera de nitrogênio, após o tratamento térmico T6 obteve uma média de microdureza de $72,30 \mathrm{HV}-50 \mathrm{~g}$. O melhor resultado encontrado foi com a pressão de $700 \mathrm{MPa}$ e dureza de 74,96 HV50g, se comparado com a microdureza encontrada no composto $\mathrm{Al} 12 \% \mathrm{Si}$ sem o tratamento térmico $\mathrm{T} 6$ observa-se que a média ficou com 59,51 HV-50g, obtendo assim um aumento de $21,5 \%$ na microdureza do composto $\mathrm{Al} 12 \% \mathrm{Si}$. 


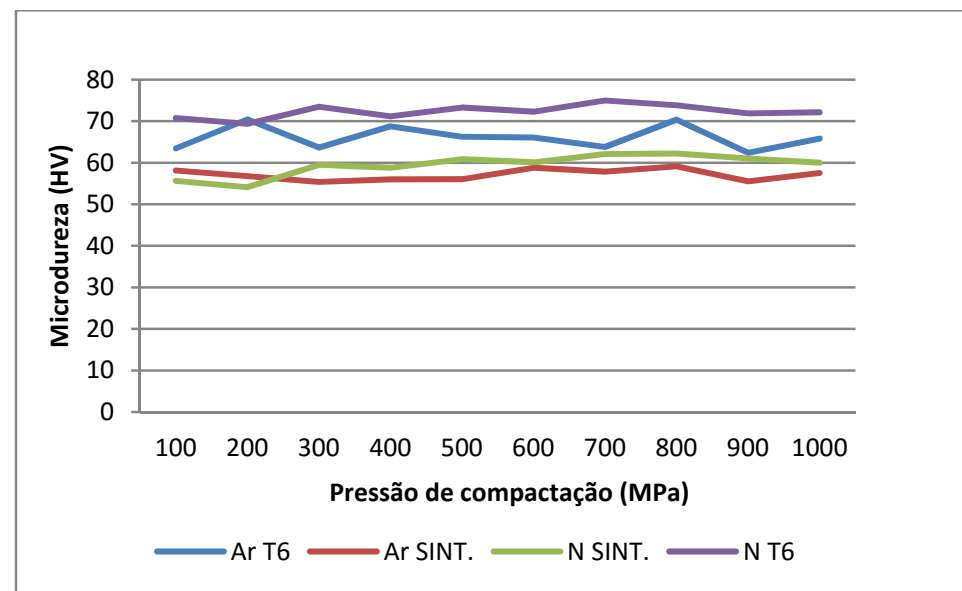

Figura 7: Comparação das microdurezas das amostras de Al12\%Si sinterizadas com nitrogênio $x$ argônio.

Analisando a Figura 7 , pode-se observar que tanto o material sinterizado com atmosféra controlada com nitrogênio quanto com argônio, após o tratamento térmico T6 obtiveram um aumanto de microdureza, porém obtendo um melhor resultado do sinterizado Al12\%Si com atmosféra de nitrogênio, que após o tratamento térmico T6 obteve uma média de microdureza de 72,30 HV-50g. Analisando os materiais que foram apenas sinterizados pode-se observar que a sinterização com atmosfera de nitrogênio também obteve um melhor desempenho em ralação a atmosfera de argônio atingindo uma microduraza com média de 59,51 HV-50g.

Identificou-se a partir da Figura 8 através da análise metalográfica que houve interação entre o $\mathrm{Al} 12 \% \mathrm{Si}$, mas não houve total interdifusão entre os elementos constituintes.

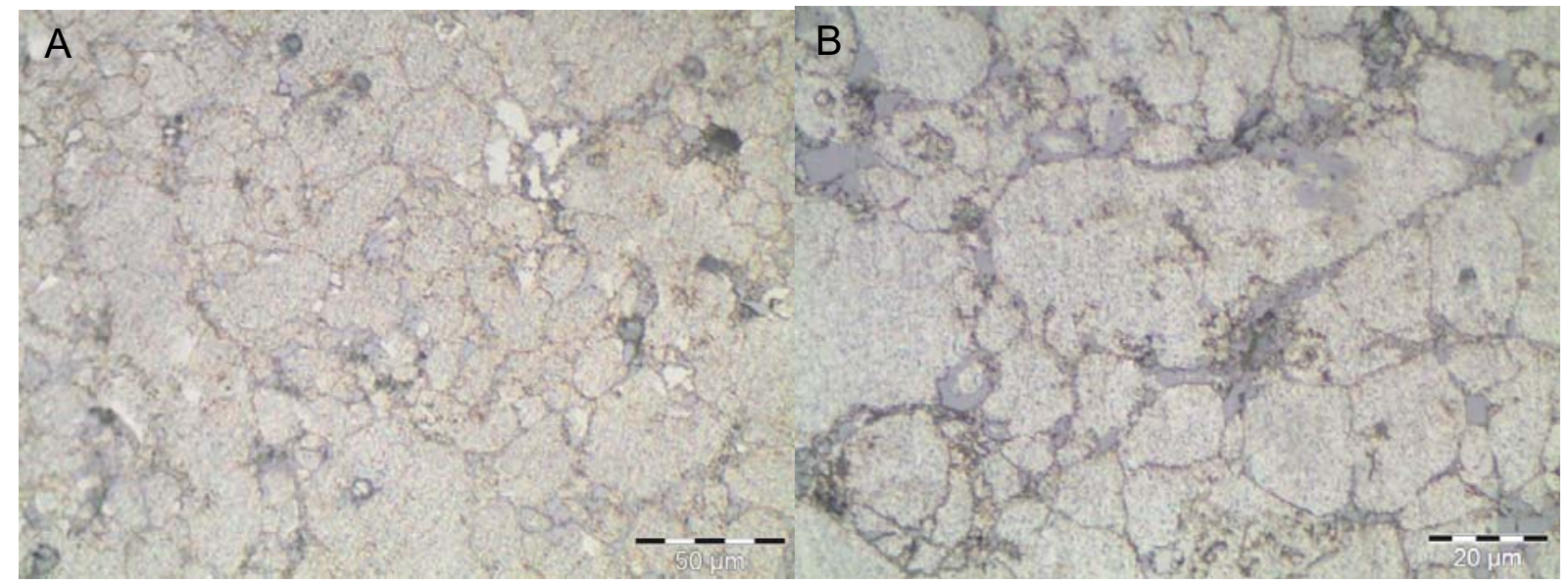

Figura 8: Metalografia do composto Al12\%Si em argônio - (A) 50 ㅆm (B) $20 \mu \mathrm{m}$.

Mesmo não havendo ataque é possível identificação do contorno de graõs das amostras sinterizadas. Observa-se a homogeneidade da porosidade mostrada na metalografia da composição do composto de Al12\%Si. Para melhor visualização da microestrutura na matriz de alumínio aumentou-se a magnificação da metalografia. Observa-se a homogeneidade da distribuição sobre a amostra com poros entre 10 a 20 um. A Figura 9 mostra o composto Al12\%Si sinterizado em nitrogênio. 


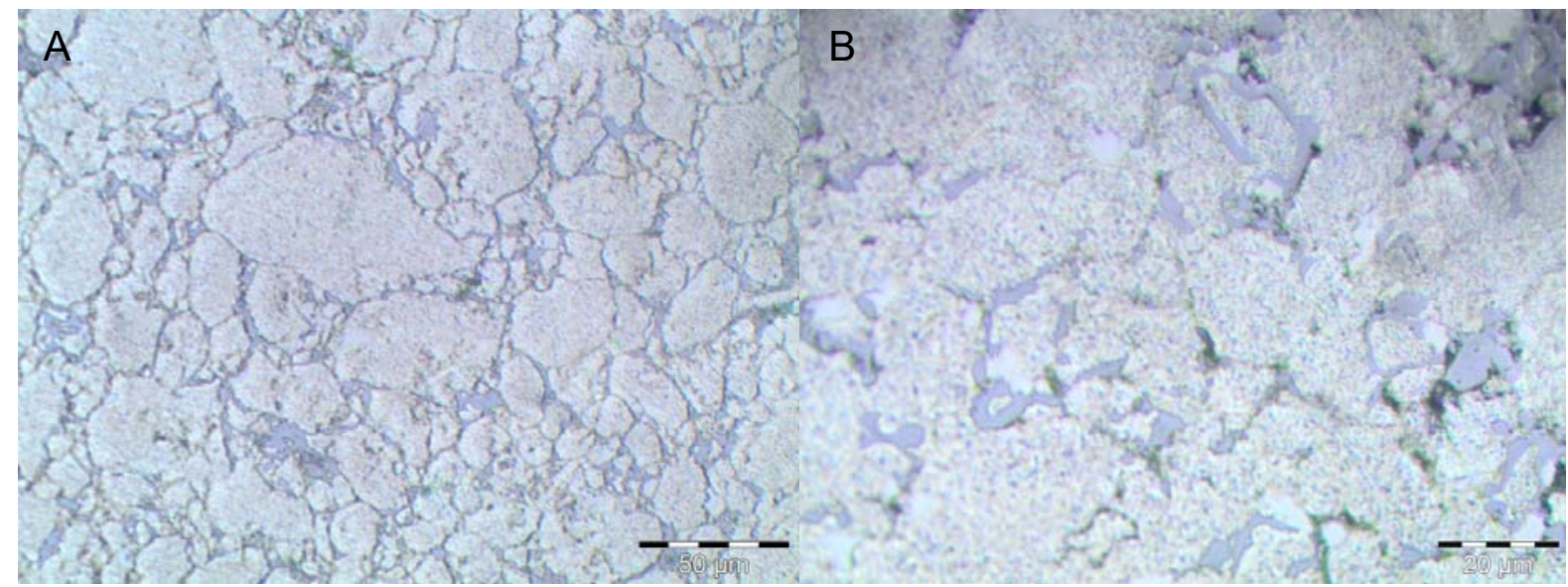

Figura 9: Metalografia do composto Al12\%Si em nitrogênio - (A) $50 \mu \mathrm{m}$ (B) $20 \mu \mathrm{m}$

Também é observado que houve interação entre os constituintes do composto Al12\%Si menos com o silício devido a sua miscibilidade e determinada através do EDS. Nota-se que as partículas de silício não difundidas estão presentes sobre toda a matriz de alumínio formando um composto intermetálico com tamanhos entre 5 e $20 \mu \mathrm{m}$.

\section{CONCLUSÃO}

Analisando os resultados encontrados observa-se que tanto o material sinterizado com atmosfera controlada com nitrogênio quanto com o argônio, após o tratamento térmico T6 obtiveram um aumento de microdureza, porém obtendo um melhor resultado do sinterizado $\mathrm{Al} 12 \% \mathrm{Si}$ com atmosfera de nitrogênio, que após o tratamento térmico T6 obteve uma média em sua microdureza de $72,30 \mathrm{HV}-50 \mathrm{~g}$, obtendo assim um aumento de $21,5 \%$ em relação ao sinterizado com argônio. Analisando os materiais que foram apenas sinterizados pode-se observar que a sinterização com atmosféra de nitrogênio também obteve um melhor desempenho em ralação a atmosfera com argônio atingindo uma microdureza com média de 59,51 HV-50g, obtendo assim um aumento de $21,09 \%$ em relação ao sinterizado com argônio. Observa-se que a densificação das amostras sinterizadas não foi maior que as amostras a verde, que apresenta devido à dificuldade quando se trabalha com o alumínio utilizando o processo de metalurgia do pó. O problema se dá devido à presença de uma camada de óxido, que envolve completamente a superfície das partículas de pó acarretando um grande prejuízo tanto na compressibilidade quanto na sinterabilidade das amostras. Analisando os dados encontrados pode-se concluir que o processo de sinterização com atmosfera controlada por nitrogênio deve ser utilizado para o processamento de peças do composto intermetálico $\mathrm{Al} 12 \% \mathrm{Si}$, trazendo melhores resultados quanto a análise de microdureza.

\section{REFERÊNCIAS}

1 SANDEROW, H.; Management \& Engineering Technologies. Powder Metallurgy Methods and Design. ASM Metals Handbook v7 - Powder Metal Technologies and Applications. ASM International, 9a Edition. 1998. p.23-24;

2 Grupo Setorial de Metalurgia do pó; A Metalurgia do Pó: Alternativa econômica com menor impacto ambiental. São Paulo: Editora Metallum $1^{\circ}$ Ed., 2009;

3 CHIAVERINI, Vicente; Metalurgia do pó: técnica e produtos, $4^{\circ}$.ed. São Paulo: 2001; 
4 SCHAEFFER, LÍRIO.; Jornal do Comércio. Publicado na edição impressa de 05/08/2010;

5 MANENTE, A., TOMELLI, G. Optimizing the Heat Treatment Process of Cast Aluminium Alloys, Recent Trends in Processing and Degradation of Aluminium Alloys, Prof. Zaki Ahmad (Ed.), ISBN: 978-953- 307-734-5, InTech, Available from:http://www.intechopen.com/books/recent-trends-in-processing-anddegradationofaluminium-alloys/optimizing-the-heat-treatment-process-of-cast-aluminiumAlloysProcess of Cast Aluminium Alloys, 2011.

6 Oliveira, R. O. M.; Rocha, O. F. L. TRATAMENTO TÉRMICO DE PRECIPITAÇÃO - T6 APLICADO EM RODA DE LIGA LEVE DE MOTOCICLETA. HOLOS, Ano 30, Vol. 5 disponivel em:

http://www2.ifrn.edu.br/ojs/index.php/HOLOS/article/viewFile/2337/pdf 116 Acesso em: 04/07/2016.

7 PIECZONKA, T.; SCHUBERT, T.; BAUNACK, S.; KIEBACK, B. Sintering Behaviour of Aluminium in Different Atmospheres. Fraunhofer Institute, 2005.

8 S.H. Huo, M. Qian, G.B. Schaffer, E. Crossin 21 - Aluminium powder metallurgy Fundamentals of Aluminium Metallurgy, 2011, Pages 655-701 